\title{
A Pilot Study on the Microbiome of Amblyomma hebraeum Tick Stages Infected and Non-Infected with Rickettsia africae
}

\author{
Dalicia Kisten ${ }^{1}$, Jory Brinkerhoff ${ }^{1,2}$, Selaelo Ivy Tshilwane ${ }^{1}$ and Samson Mukaratirwa $1,3, *$ (D) \\ 1 School of Life Sciences, Biological Sciences Section, College of Agriculture, Engineering and Science, \\ University of KwaZulu-Natal, Westville Campus, Durban 4000, South Africa; dalicia3@gmail.com (D.K.); \\ jbrinker@richmond.edu (J.B.); TshilwaneS@ukzn.ac.za (S.I.T.) \\ 2 Department of Biology, University of Richmond, Richmond, VA 23173, USA \\ 3 One Health Center for Zoonoses and Tropical Veterinary Medicine, Ross University School of Veterinary \\ Medicine, Basseterre 42123, Saint Kitts and Nevis \\ * Correspondence: mukaratirwa@ukzn.ac.za
}

Citation: Kisten, D.; Brinkerhoff, J.; Tshilwane, S.I.; Mukaratirwa, S. A Pilot Study on the Microbiome of Amblyomma hebraeum Tick Stages Infected and Non-Infected with Rickettsia africae. Pathogens 2021, 10, 941. https://doi.org/10.3390/ pathogens 10080941

Academic Editor: Claude Saegerman

Received: 25 May 2021

Accepted: 2 July 2021

Published: 27 July 2021

Publisher's Note: MDPI stays neutral with regard to jurisdictional claims in published maps and institutional affiliations.

Copyright: (c) 2021 by the authors. Licensee MDPI, Basel, Switzerland. This article is an open access article distributed under the terms and conditions of the Creative Commons Attribution (CC BY) license (https:// creativecommons.org/licenses/by/ $4.0 /)$.

\begin{abstract}
Variation in tick microbiota may affect pathogen acquisition and transmission but for many vector species, including Amblyomma hebraeum, components and determinants of the microbiome are unidentified. This pilot study aimed to determine baseline microbial community within A. hebraeum nymphs infected- and non-infected with Rickettsia africae from the environment, and within adult ticks infected- and non-infected with $R$. africae collected from cattle sampled from two locations in the Eastern Cape province of South Africa. Adult A. hebraeum ticks $(\mathrm{N}=13)$ and A. hebraeum nymph $(\mathrm{N}=15)$ preliminary screened for $\mathrm{R}$. africae were randomly selected and subjected to Illumina sequencing targeting the $\mathrm{v} 3-\mathrm{v} 4$ hypervariable regions of the $16 \mathrm{~S}$ rRNA gene. No significant difference in microbial community composition, as well as rarefied OTU richness and diversity were detected between adults and nymphs. Nymphs showed a higher richness of bacterial taxa indicating bloodfeeding could have resulted in loss of microbial diversity during the moulting stage from nymph to adult. Core OTUs that were in at least $50 \%$ of nymphs and adults negative and positive for Rickettsia at $1 \%$ minimum relative abundance were Rickettsia, Coxiella and Ruminococcaceae UCG-005 with a single genus Arsenophonus occurring only in nymphs negative for Rickettsia. Ehrlichia spp. was present in only four nymphal ticks positive for Rickettsia. Interestingly, Rickettsia aeschlimannii was found in one nymph and one adult, indicating the first ever detection of the species in A. hebraeum. Furthermore, $A$. hebraeum harboured a Coxiella-like endosymbiont, which should be investigated further as Coxiella may affect the viability and transmission of other organisms.
\end{abstract}

Keywords: Amblyomma hebraeum; bacteria; microbiome; nymph and adult ticks; Rickettsia africae infection; Rickettsia aeschlimannii

\section{Introduction}

Tick-borne diseases are caused by a variety of microbial agents including viruses, protozoa and bacteria [1,2]. Ticks act as reservoirs for a variety of microbial communities and only a few have been studied [3]. Microbial interactions in vectors can affect pathogen transmission or persistence in the vector, hence, the vector microbiome is important to understanding disease risk and dynamics. However, the microbiome is impacted by multiple factors which include host species, location, life stage, and pathogen presence. Amblyomma hebraeum is one of the major tick species in South Africa and has been reported to be an efficient vector of a variety of pathogens in animals and humans [4]. It is a threehost-tick belonging to the family Ixodidae $[4,5]$ and apart from transmitting pathogens in livestock and humans it causes major damage to livestock through its bites thereby decreasing animal productivity [4]. The major pathogens transmitted by this tick species are R. africae (human) and Ehrlichia ruminantium (cattle/wildlife) $[4,6]$. The genus Rickettsia includes numerous tick-borne pathogens [1,7], including some that are zoonotic [8], but it 
also contains non-pathogenic endosymbiont species $[3,9,10]$. Although, they are known to be treatable with doxycycline, there remains a difficulty in clinical diagnosis of rickettsiosis, due to the variety of symptoms posed by these organisms [11,12], although, many rickettsioses present with macular erythematous rash that may extend over much of the body surface.

The microbial diversity in a tick may vary in ticks based on factors such as species, geographical location and environmental factors including temperature, humidity, season and habitat type, as well as the stage or sex of the tick and the host(s) involved in the life cycle $[13,14]$. Although the tick microbiome collectively includes microorganisms, such as viruses, eukaryotes and other tick-borne pathogens, the focal point of microbiome research has been on Eubacteria [9]. Microbiome studies of ticks are increasing in number, and patterns are being identified, but there is still much to be learnt about the factors that affect microbiome composition [15].

There is limited information on the microbial communities of these ticks and as to whether certain bacterial families within the microbiome of A. hebraeum, may influence the transmission of Rickettsia spp. The identification of bacterial communities that constitute the microbiome of a given species of a tick is fundamental to exploring its functions and few studies have been attempted in this regard $[2,10]$. Studies conducted on $A$. hebraeum have primarily focused on detection of tick-borne pathogens such as Anaplasma spp., Ehrlichia ruminantium, Theileria spp. and Rickettsia spp., and hence, there is paucity of research pertaining in the role of the microbiome and the bacteria it constitutes [16].

In addition to this, some studies have demonstrated that all stages in the life cycle of $A$. hebraeum are equally able to transmit Rickettsia infection to livestock [17]. Due to the current understanding of the microbial community in A. hebraeum, it is necessary to understand whether the microbiome differs by life stage of A. hebraeum that lead to infection of $R$. africae [17]. Furthermore, it has been argued that although the relative abundance of tick-borne diseases on species has previously been studied as a basis for intervention, the direct and indirect damage from these tick-borne diseases can be avoided with better information on the composition of tick microbial communities and how they affect pathogen transmission [18]. This information can help in understanding the potential transmission of certain species of Rickettsia, such as $R$. africae with regard to the locality, seasons and environmental conditions from which they are collected $[17,18]$.

This study focused on identifying baseline microbiome information in the nymph and adult stages of $R$. africae-infected and non- $R$. africae-infected $A$. hebraeum from a selected locality in the Eastern Cape province of South Africa.

\section{Results}

\subsection{Tick Identification and Status of Infection with R. africae}

Some ticks that were preliminarily screened as negative for Rickettsia spp. by the process of PCR, tested positive after Illumina sequencing. This could be due to Illumina sequencing being relatively more sensitive compared to PCR, and another reason could be the inability of PCR in identifying certain lineages of Rickettsia as the species is so diverse.

Upon morphological classification of ticks sampled from cattle and pastures from Lucingweni, Eastern Cape, no ticks were found that belonged to the genus Amblyomma. In total, microbiomes for 28 A. hebraeum ticks were characterized: 14 adult $A$. hebraeum were collected from cattle and 14 nymph $A$. hebraeum were collected by drag sampling from Caquba, Eastern Cape (Table A1). PCR and sequencing were carried out for all 28 samples. Analysis of the microbiome data showed a total number of 13,729,994 sequences (range $=10,020-255,352$ ), a mean of 49,036 and median of 22,1715 of which 7850 were unique sequences acquired from all 28 samples. The sequence count showed that even though the sequence variants were different (e.g., different forms of Rickettsia) they shared the same genus level. Similar sequences were therefore clustered at $99 \%$ similarity to form a final count of 301 OTUs. Sequences that did not fall into any taxon within the Kingdom Bacteria $(\mathrm{N}=996)$ were clustered into an "unassigned" folder. 


\subsection{Microbial Community Structure}

The Shapiro-Wilk normality test indicated the data did not follow a normal distribution $(p=0.001)$. Microbiome composition did not vary significantly between nymphs and adults negative for $R$. africae (PerMANOVA: $\mathrm{F}=1.0791, p=0.282$; Figure $1 \mathrm{~A}$ ) or between nymphs and adults positive for $R$. africae (PerMANOVA: $\mathrm{F}=0.7356, p=0.723$; Figure 1B) as well as between all nymphs (positive and negative) and adults (positive and negative) (PerMANOVA: $\mathrm{F}=0.8795, p=0.492$; Figure $1 \mathrm{C}$ ). Rarefied OTU richness did not vary significantly between $A$. hebraeum nymphs and adults, which were negative for $R$. africae $(p>0.05, \mathrm{~T}=-1.70$; Figure 2), as well as between nymphs and adults which were positive for R. africae ( $p>0.05, \mathrm{~T}=-0.93$; Figure 2$)$.
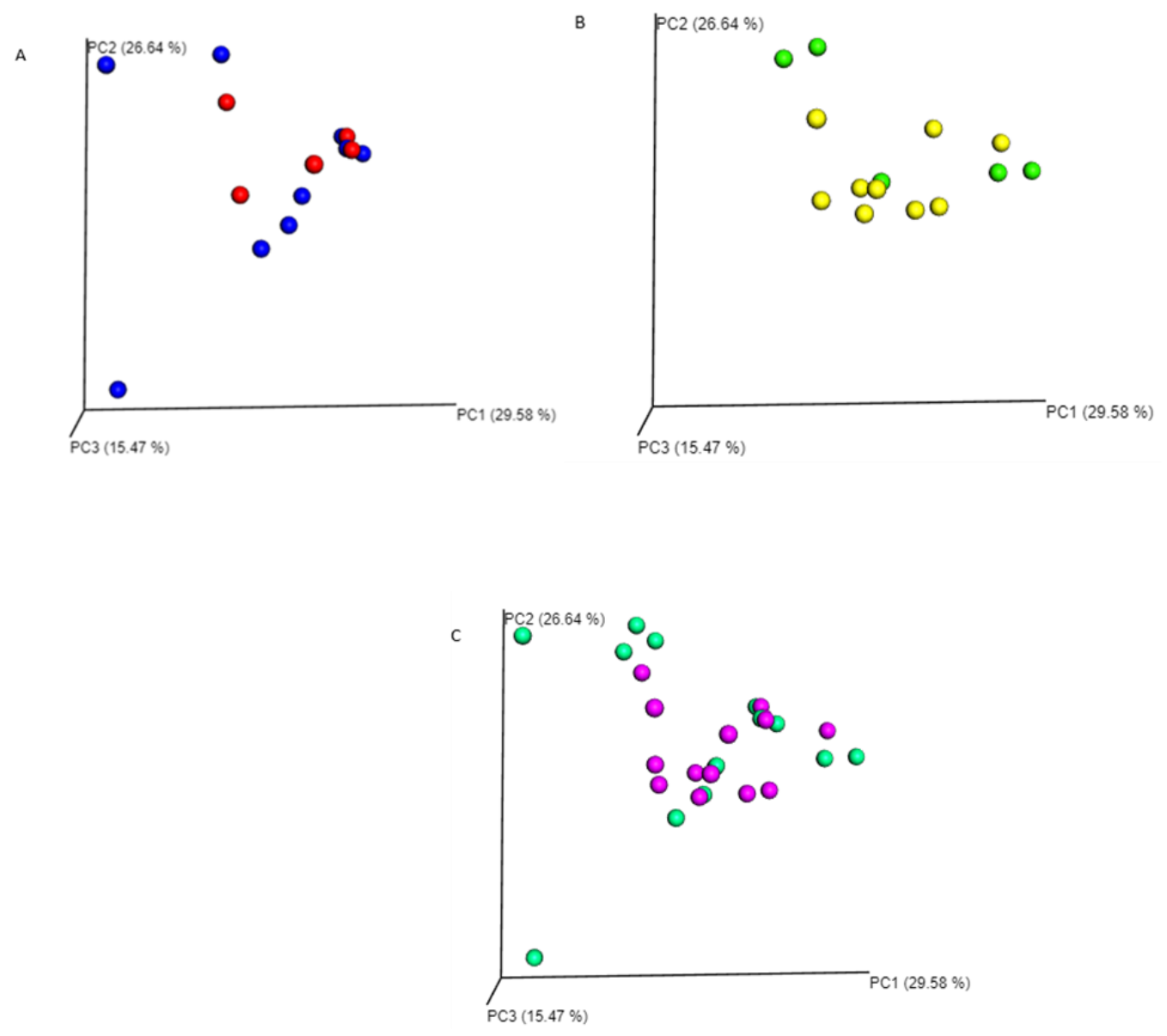

Figure 1. Weighted unifraction plots for Amblyomma hebraeum nymphs and adults negative and positive for Rickettsia africae. (A)-Negative nymphs and adults (adults are red, nymphs are blue), (B)-positive nymphs and adults (adults are yellow, nymphs are green), (C)-Combined nymphs and adults (positive and negative) (adults are purple, nymphs are green).

The analysis of alpha diversity measures using a pairwise-Wilcoxon test showed no significant difference between negative nymphs and adults $(p>0.05, \mathrm{~T}=1.02)$ (Figure A1 in Appendix A) and positive nymphs and adults $(p>0.05, \mathrm{~T}=0.42)$. Using raw data, the anosim $R$ value when comparing the mean of ranked dissimilarities within groups to the mean of ranked dissimilarities between groups indicated an even distribution of high and low ranks for both negative and positive nymphs, and adults, respectively $(\mathrm{R}$ statistic $=-0.04 ; \mathrm{R}$ statistic $=0.36)$. The closer the $\mathrm{R}$ value is to zero the more similar the microbial composition between adults and nymphs. Negative nymphs and adults showed no significant difference in microbial communities between and within groups $(p=0.58)$. While positive nymphs and adults showed statistically significant difference in microbial communities within groups rather than between $(p=0.02)$. The complemented NMDS plot (Figure 3) showed an overlap between OTU bacterial composition for negative 
nymphs and adults and positive nymphs and adults which correlated with anoism and PerMANOVA outputs. The stress of 0.104 indicated a good level of ordination in terms of reduced dimensions. Rarefaction curves (Figure A2A,B) are illustrated using the mean species diversity of bacterial composition in OTUs for positive nymphs and adults, and negative nymphs and adults. Both rarefaction curves indicated that majority of samples did not approach the saturation plateau, and hence, there was not enough coverage to represent all bacterial populations.

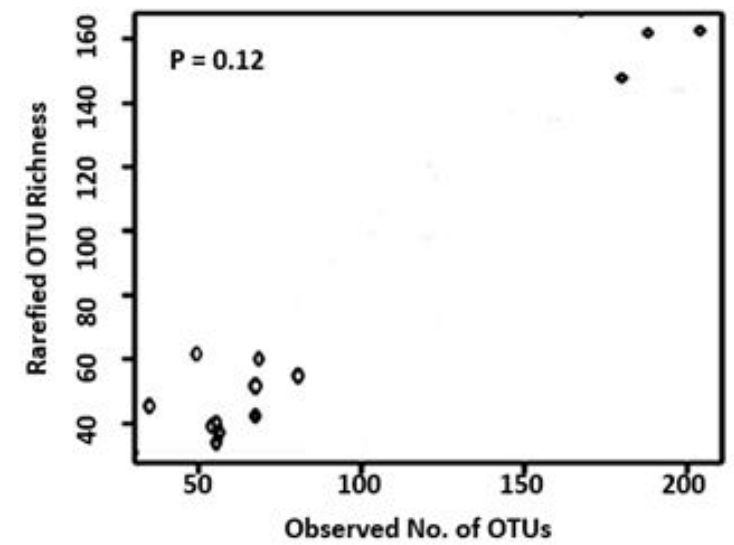

Rickettsia positive nymphs and adults

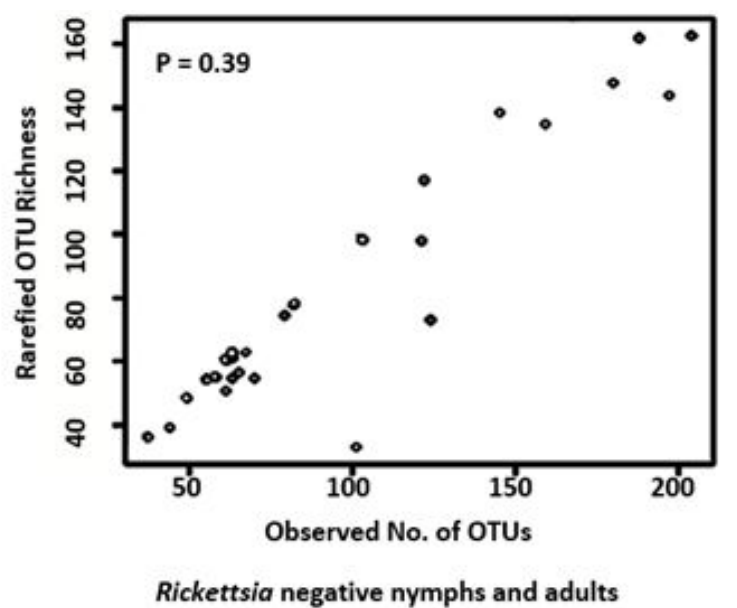

Figure 2. Rarefied OTU richness of Amblyomma hebraeum nymphs and adults negative and positive for Rickettsia africae. Dots indicate observed OTUs. The $p$-value indicates the significance level.

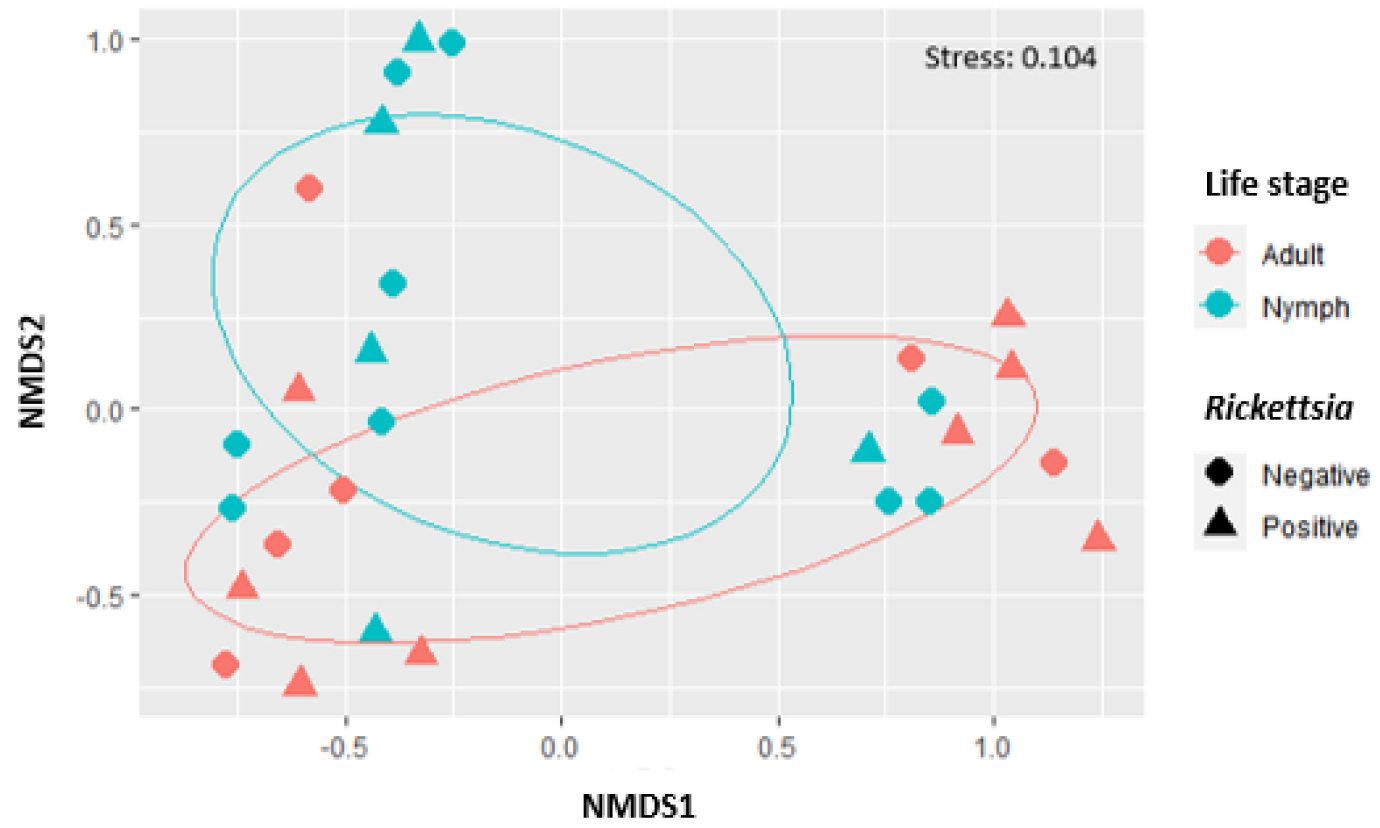

Figure 3. Non-metric multidimensional scaling (NMDS) ordination plot of OTU bacterial composition in Amblyomma hebraeum nymphs and adults negative and positive for Rickettsia africae. Colors pink and blue indicate life stage and shapes indicate Rickettsia status. The stress value was 0.104 . Ellipses indicate the $95 \%$ confidence interval around the centroid in nondimensional space.

\subsection{Taxonomic Differences}

The initial summary of OTUs for the negative group was 301 taxonomic classifications in 15 samples and for positive group, 301 taxonomic classifications in 13 samples. After utilizing the phyloseq prune function the taxa were reduced to 271 taxonomic classifications in the negative group and 226 taxonomic classifications in the positive group. Phyla that 
showed the highest relative abundance within the negative and positive groups respectively were Firmicutes $(33.95 \%)$ and $(35.40 \%)$, Proteobacteria $(29.52 \%)$ and $(30.09 \%)$, Bacteroidetes $(17.34 \%)$ and $(16.81 \%)$ followed by lower percentages in Actinobacteria $(7.01 \%)$ and $(5.75)$ and Tenericutes $(2.58 \%)$ and $(3.10 \%)$ and some phyla contributed percentages of $1 \%$ and below (Figure 4). The genus Rickettsia (phylum Proteobacteria) was detected in $96.43 \%$ of ticks (27 of 28) across all samples including samples that initially tested negative during PCR (Figure 5). Nymphs had a higher richness of microbial communities as compared to adults (Figure 6). Further analysis of relative richness of bacterial community boxplots using the phyloseq psmelt function separated the adults from the nymphs for negative and positive samples (Figure A3) emphasizing the high counts of Firmicutes, Proteobacteria and Bacteroidetes. A Venn diagram was used to evaluate the similarities between the two groups, defined as core OTUs at genus level present in at least $50 \%$ of negative nymphs and adults (Figure 7A) and positive nymphs and adults (Figure 7B) at $1 \%$ minimum relative abundance. Only one genus, Arsenophonus, belonging to the phylum Proteobacteria was specific to negative nymphs whilst the overlap revealed that both nymphs and adults shared genera Coxiella (Proteobacteria), Ruminococcaceae UCG-005 (Firmicutes), Rickettsia (Proteobacteria) and "Other" (Sequences that were not classified into a known phylum). There were no genera distinctive to either positive nymphs or adults, whilst the overlap showed they shared genera Rickettsia, Coxiella, family Ruminococcaceae UCG-005 and "Other".

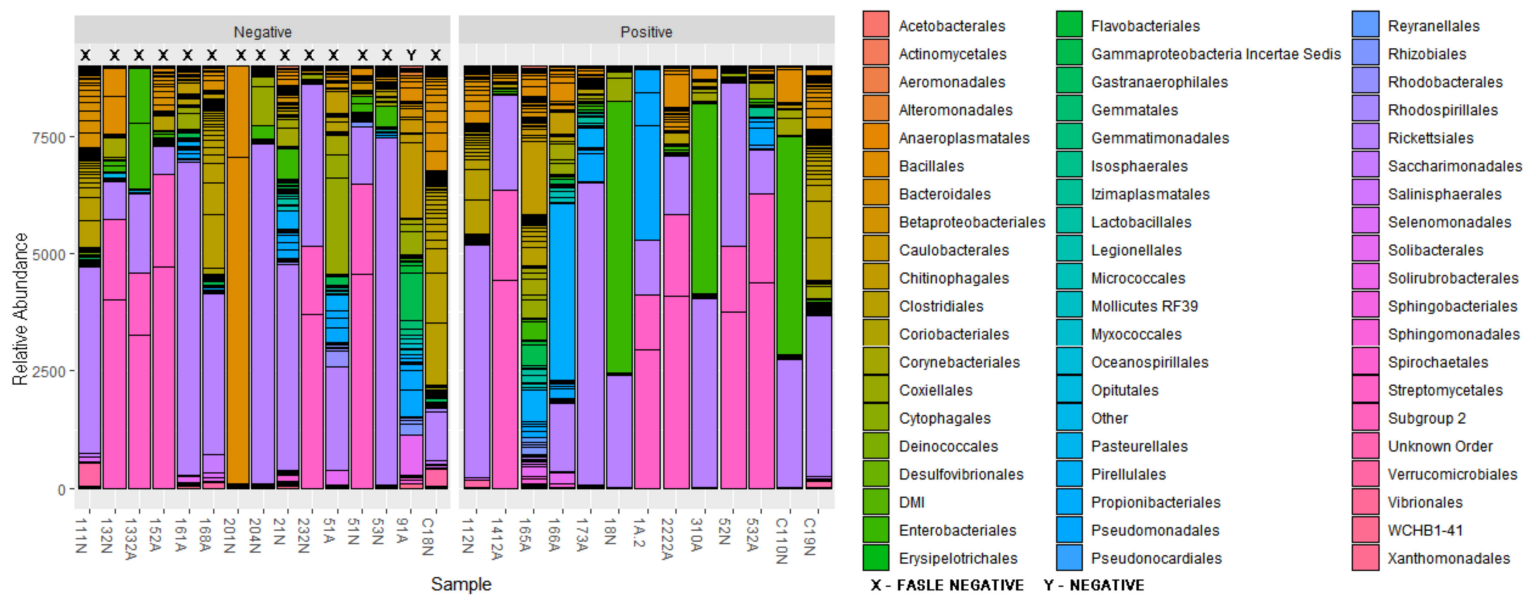

Figure 4. Relative abundance of bacterial communities according to order classification for Amblyomma hebraeum nymphs and adults negative and positive for Rickettsia africae. X-False negative samples, Y-Negative sample.

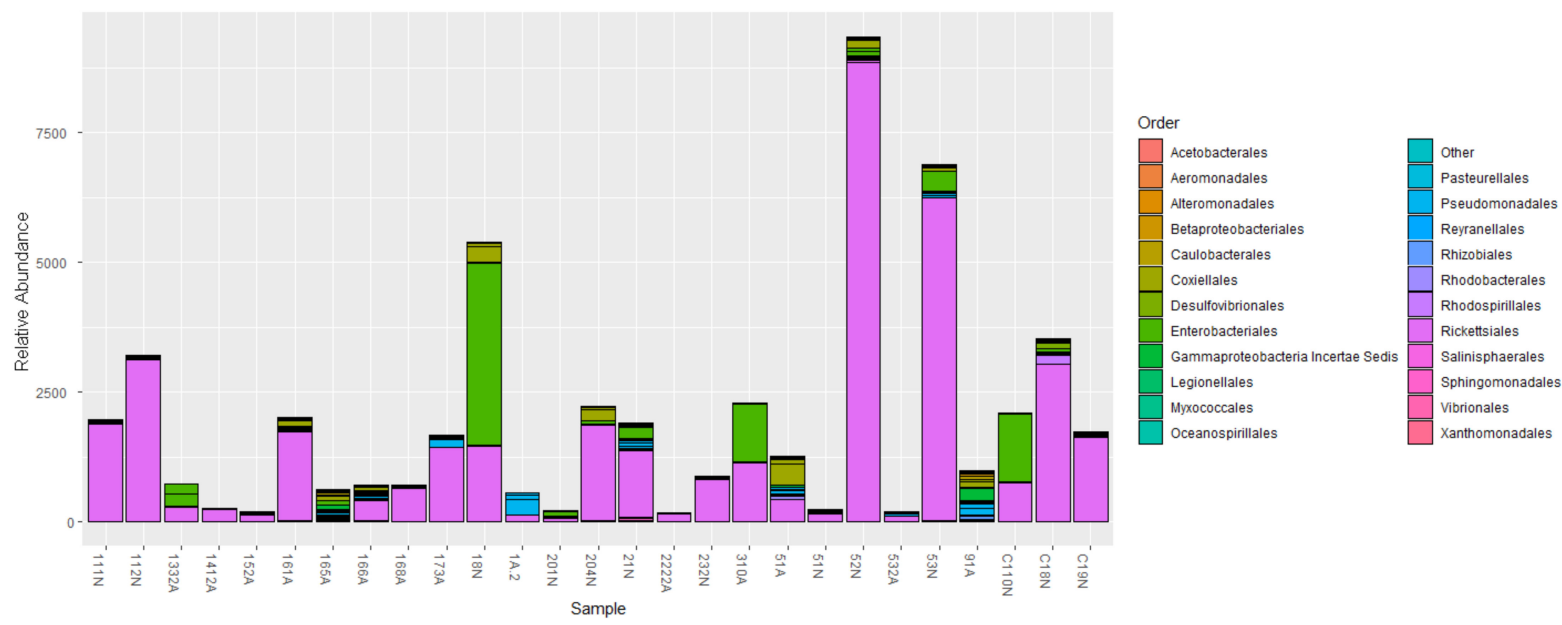

Figure 5. Relative abundance of bacterial communities according to order classification within the phylum Proteobacteria for Amblyomma hebraeum nymphs and adults negative and positive for Rickettsia africae. 


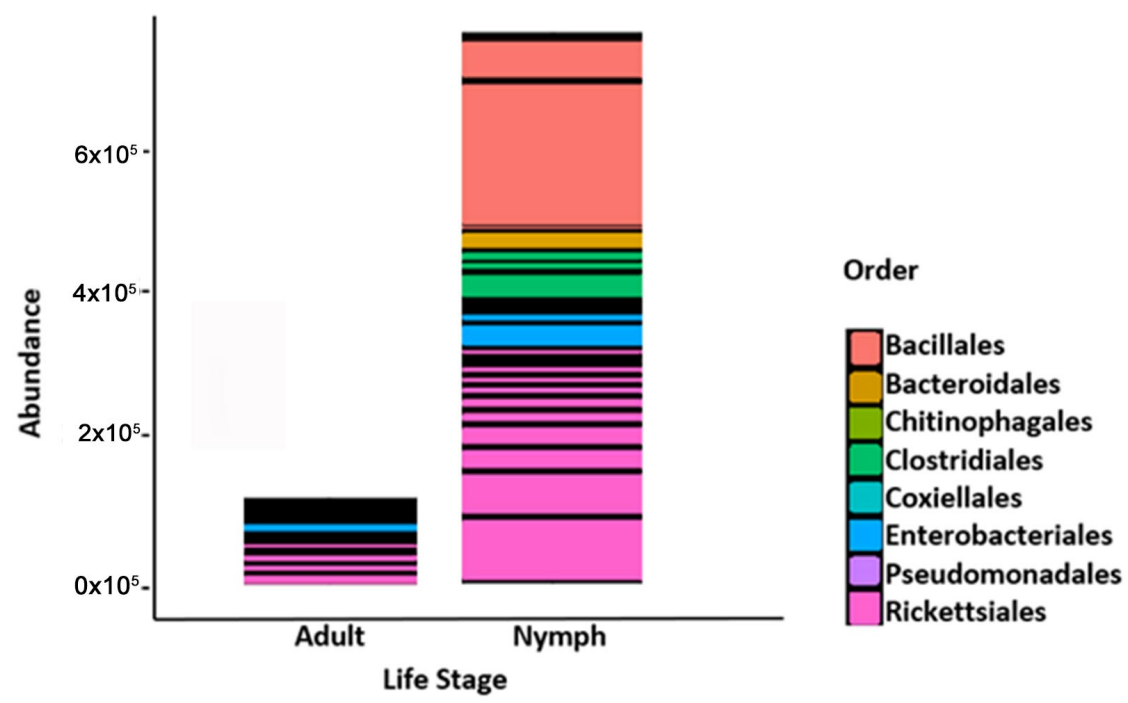

Figure 6. Relative abundance bar plot representing bacterial communities according to order classification for Amblyomma hebraeum nymphs and adults negative and positive for Rickettsia africae.
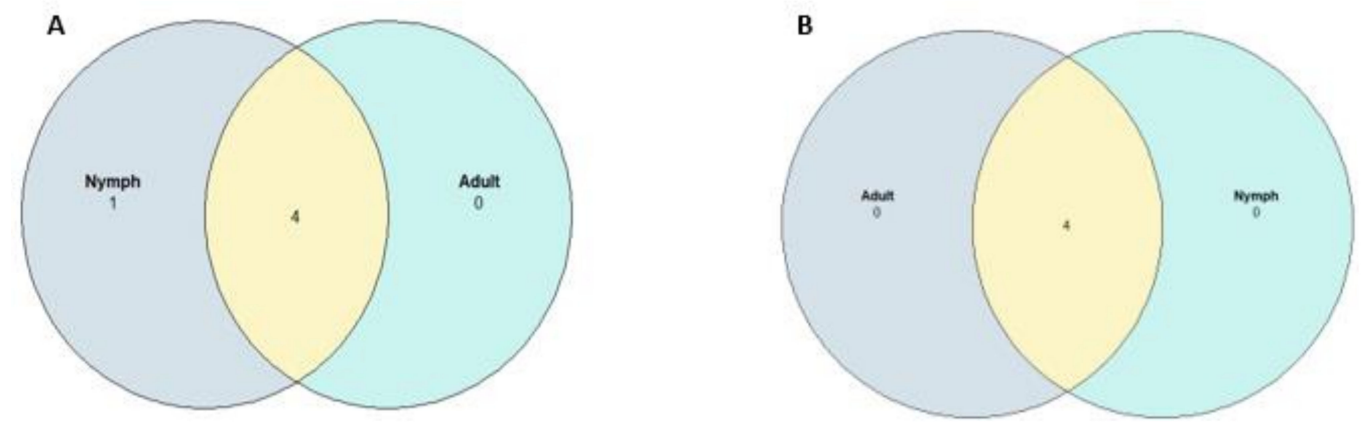

Figure 7. Core OTUs defined as genus present in at least 50\% of Amblyomma hebraeum nymphs and adults negative and positive for Rickettsia africae at 1\% minimum relative abundance. (A) Nymphs and adults negative for Rickettsia, one genus (Arsenophonus) specific to negative nymphs (A-overlap)-Coxiella, Ruminococcaceae UCG-005, Rickettsia and "Other". (B) Nymphs and adults positive for Rickettsia (B-overlap)-Coxiella, Ruminococcaceae UCG-005, Rickettsia and "Other".

\section{Discussion}

The aim of this study was to determine the microbiota community present within A. hebraeum nymphs (collected from the environment), and adult ticks (collected from cattle) infected with $R$. africae and from the non-infected stages in Caquba locality in the Eastern Cape province of South Africa. The results from the study showed no significant differences in OTU richness and diversity between nymphs and adults positive and negative for $R$. africae. This was corroborated by the minimal sequencing depth of the samples with most OTUs having a bacterial composition less than 50,000 sequences and only a few OTUs having more than 200,000 sequences. As previously demonstrated, a compromise must be made between the precise measure of species diversity and the relative abundance and how rarefaction is used to lessen the negative outcome of uneven sampling effort [19]. A previous study revealed similar results to our study regarding lack of OTU richness and diversity of Anaplasma / Ehrlichia positive and negative ticks although there was presence of variation in represented OTUs [20].

Some samples that were initially screened as negative for R. africae during PCR [21] were later shown to be positive during Illumina sequencing probably due to the process being relatively more sensitive and able to analyze trace amounts of Rickettsia sequences and diverse lineages [22]. It has been highlighted in some studies that commercially supplied 
DNA extraction kits used for PCR could possibly contain bacteria, which negatively hinder the downstream analysis during sequencing hence this may have affected the Rickettsia status as well [23].

Our study showed that microbial constituents of nymphs and adult ticks were shared between the two life stages and offered very little variation. Insignificant difference was found between microbiome variation between nymphs and adults. This is likely due to the close geographic proximity of the sampling sites in Caquba as microbial diversity in ticks has been shown to vary with geographic location, environmental factors and species identity. Various studies have shown that the closer sampling sites are to each other, the less distinct the microbial composition within a particular tick species is likely to be $[13,14,19]$.

Tick microorganism variation is likely to be increased by those organisms transmitted from the animal to the tick whilst blood feeding, as well as the soil or pasture that immature stages are sampled from [3]. This is supported by results [20], which showed that tick microbiota differed at sites with different soil types, but soil type was not considered in this study, as well as the species of tick host, including sampling of different regions.

Analysis of OTU relative abundance showed a total of fourteen phyla that were shared between nymphs and adults. From the fourteen phyla, Firmicutes, Proteobacteria and Bacteroidetes dominated the samples in this study, and this agrees with previous studies, which showed that tick microbiota found in A. hebraeum mainly consists of the same three phyla in varying amounts $[9,13,14,24]$. Similar results have also been reported regarding the microbiome of $A$. americanum [19,20] and of Amblyomma maculatum [25].

Positive nymphs and adults had a higher composition of Firmicutes compared to negative nymphs and adults. Within the phylum Firmicutes were 44 genera and 17 species with one of the core genera being Ruminococcaceae UCG-005 with an unclassified species. Nymphs had a high relative abundance of Orders Bacilalles and Clostridiales and in accordance with a previous study by Clow et al. [26] who reported Ruminococcaceae as one of the most dominant families in Ixodes scapularis and Dermacentor variabilis. Clostridiales has also been reported as the dominating group in tick species infesting livestock in Pakistan [27].

Proteobacteria accounted for the second highest percentage of bacterial composition with the genus Rickettsia having the highest abundance. They were detected in $96.43 \%$ of ticks (27 of 28) across all samples including samples that initially tested negative during PCR. It was assumed Rickettsia spp. would dominate the samples as A. hebraeum is the principal vector of $R$. africae, evidently the study conducted by Magaia et al. [28] confirmed that $80 \%$ of $A$. hebraeum ticks were infected with $R$. africae in Mozambique. As with other taxa presented in this study, nymphs had a higher relative abundance of Rickettsia spp. and this is consistent with report by Jongejan et al. [18] who found that $R$. africae was present in adult and nymph Amblyomma ticks at $15.7 \%$, and $40 \%$, respectively. The high relative abundance of Rickettsia spp. in nymphs can also be explained by the vertical transmission of the bacterium from egg masses to larvae then to nymph $[7,19,29]$. By comparing the life stages, nymphs showed richness in bacterial composition when compared to adults and this could be due to the possibility of the loss of some bacterial composition from the time the nymph starts to moult to 100 days after it has reached its adult stage [19,30].

We anticipated a higher percentage of Ehrlichia spp. positive samples in this study, however, the family Anaplasmataceae were present in only four nymphs. This is in accordance with Jongejan et al. [18] who reported co-infection of E. ruminantium and R. africae in $14.9 \%$ of nymphs in South Africa. The finding of Ehrlichia spp. in nymphs collected from the environment is in contrast with Mtshali et al. [31]. who found that questing nymphs were negative for Ehrlichia spp.

Interestingly, R. aeschlimannii was found in a single $A$. hebraeum adult and nymph. There are no previous reports that have indicated $A$. hebraeum being a carrier for $R$. aeschlimannii. A study conducted by Pretorius et al. [32] reported the first occurrence of $R$. aeschlimannii in R. appendiculatus in South Africa. Rhipicephalus (B.) microplus and an unidentified Rhipicephalus species were present in cattle along with $A$. hebraeum. Whilst, sampling in our study area and a 
possible transference of microbiota between two different species of ticks during blood feeding on the same host is uncertain but not unlikely. Comparably, significant microbiome variation in I. scapularis and D. variabilis has been reported even though the ticks fed on the same host [24]. Further analysis on the genus Rhipicephalus sampled from the same location could provide insight on the Rickettsia lineages and the presence of R. aeschlimannii.

A singular genus specific to only nymphs negative for Rickettsia at $50 \%$ relative abundance was Arsenophonus belonging to the phylum Proteobacteria. Notably, Arsenophonus nasoniae has been associated with ticks belonging to the genera Amblyomma and Dermacentor locate in the United States of America [10]. The extensive distribution of Arsenophonus-like endosymbionts within A. americanum was similar to that found within D. variabilis and molecular analysis of Ixodes ricinus ticks, showed 37\% of nymphs contained a strain of the Arsenophonus bacterium as compared to the adult ticks which contained only 3.6\% [33]. The study proposed that the occurrence of Arsenophonus is much higher in the immature stages of these hard ticks, which might explain its presence in the nymphal stages in the present study.

The genus Coxiella also belonging the phylum Proteobacteria had Jongejan et al. [18] infection rate in all ticks (nymph and adult). This outcome is comparable with Mtshali et al. [31] who found absence of $C$. burnetti in ticks sampled from Eastern Cape Province of South Africa but was present in ticks sampled from Kwa-Zulu Natal, Free State and Mpumalanga provinces of South Africa. Although, the infection rate recorded was 7\%. The species of the Coxiella symbiont in the present study could not be identified however its suggestive it could be closely related to the most common species in South Africa being C. burnetti the causative agent for $Q$ fever, which has been commonly detected in numerous hard ticks one of them being the genus Amblyomma [10,34]. Evidence provided by Simpson et al. [34] indicated a high seroprevalence of $60.9 \%$ for $\mathrm{Q}$ fever in farmers and $37.8 \%$ in malaria-negative acute febrile illness patients in Mpumalanga. The genus Coxiella has been commonly found in A. hebraeum, prevalent across many locations across South Africa, vertically transmitted and is considered an endosymbiont of potential importance $[10,20,34]$.

It is important to note that non-pathogenic organisms play an important role within the tick microbiome and specific non-pathogenic symbionts affect tick-borne pathogen transmission through competition or gene transfer [20]. For instance, Coxiella and Rickettsia spp. are considered non-pathogenic, but some of them are known to be tick-borne pathogens which affect humans and animals [20]. Coxiella spp. identified in their study by TroutFryxell and DeBruyn [20] may be an obligate endosymbiont. Although, it was only present in $74 \%$ of samples, this inherently suggested that if Coxiella is dependent on the tick host, the tick host is not dependent on Coxiella. Similarly in this study, Coxiella was present in $96.43 \%$ of specimens meaning it is not an obligate endosymbiont.

Authors should discuss the results and how they can be interpreted from the perspective of previous studies and of the working hypotheses. The findings and their implications should be discussed in the broadest context possible. Future research directions may also be highlighted.

\section{Materials and Methods}

\subsection{Study Site}

Sampling of $A$. hebraeum ticks was conducted between July 2018 to July 2019 in the Eastern Cape Province of South Africa. Ticks were collected from two study sites namely, Lucingweni (latitude/longitude 31.459111/28.756333) in Mthatha which is inland, and Caquba (latitude/longitude 31.6425/29.460028) in Port St Johns located along the coastline as previously described [21]. The sampling entailed tick collection from cattle (partly engorged adult ticks) and nymphs from the environment at 2 replicate quadrants at each site where quadrant was $50 \times 100 \mathrm{~m}$.

\subsection{Tick Collection}

Ticks questing on pastures were collected by drag sampling which entailed dragging $2.5 \mathrm{~m} \times 1.5 \mathrm{~m}$ cloths through the vegetation along a $50 \times 100 \mathrm{~m}$ quadrant. Nymphs were 
removed from the drag cloth using forceps and transferred into a glass vial containing $70 \%$ ethanol for further processing.

At each location, indigenous cattle were herded into a cattle crush/dipping race and once secured, adult $A$. hebraeum ticks were physically pulled-off the cattle using blunttipped forceps. Common sites of predilection of attachment of the ticks were the legs, tail, upper perineum (base of the tail and below the anus) and lower perineum (base of the scrotum). Ticks collected from each animal were placed in separate labelled glass vials containing $70 \%$ ethanol. On the label, we recorded the identification number of the animal, the sample site, date of collection and name of collector. The vials with preserved ticks were kept at room temperature until they were processed in the laboratory.

\subsection{Processing of Ticks for Analysis}

Collected ticks were morphologically identified to species level [5]. The samples were then frozen at $-80{ }^{\circ} \mathrm{C}$ until DNA extraction. Before DNA extraction, samples were removed from the freezer and allowed to thaw at room temperature. An amount of $600 \mu \mathrm{L}$ of $95 \% \mathrm{EtOH}$ was added to the sample tubes and vortexed for 30 seconds. The EtOH was decanted, and the tube was refilled with $600 \mu \mathrm{L}$ of distilled water and vortexed for $15 \mathrm{~s}$. The distilled water was decanted, and the samples were air-dried for $10 \mathrm{~min}$. The ticks were bisected from the mouth parts to the festoons. One half of the tick was placed into a $1.5 \mathrm{~mL}$ Eppendorf tube for DNA extraction and the other half stored in the freezer at $4{ }^{\circ} \mathrm{C}$ till further use. Glass beads of $0.1 \mathrm{~mm}$ diameter were placed in Eppendorf tubes containing tick samples for DNA extraction and then placed in a bead beater (Disruptor Genie, Scientific Industries, Inc, New York, NY, USA) for 2 min at 3000 rpm.

\subsection{DNA Extraction}

Half the portion of each tick was screened for $R$. africae infection using an established protocol and published primers [21] and from the outcome of screening (Table A1), 13 positive ( 8 adults and 5 nymphs) and 15 negative nymphs and adult ( 6 adults and 9 nymph) A. hebraeum were randomly selected from the screened pool for DNA extraction before running PCR with $16 S$ rRNA primers. DNA extraction was done using ZYMO Quick-DNA Miniprep Plus Kit (ZYMO Research, Orange, CA, USA) according to a modified version of the manufacturer's protocol. Samples were incubated at $56{ }^{\circ} \mathrm{C}$ for $12 \mathrm{~h}$ until the sample tissue was fully digested instead of three hours as stated in the protocol.

\subsection{PCR Amplification of Bacterial Taxa in A. hebraeum Ticks}

A 16S rRNA gene sequence analysis for the detection of sequence differences in the hypervariable regions, which are present in all bacteria, was used. Studies show that hypervariable V3-V4 regions show the most representative taxonomic bacterial profiles found in ticks [35]. PCR conditions were carried out following the protocol described in 16S Metagenomic Sequencing Library Preparation manual (Illumina, 2013). Locus-specific primers were attached to Illumina overhang adapter nucleotide sequences; forward primer.

5'-TCGTCGGCAGCGTCAGATGTGTATAAGAGACAGCCTACGGGNGGCWGCAG$3^{\prime}$ and reverse primer: 5'-GTCTCGTGGGCTCGGAGATGTGTATAAG AGACAGGACTACHVGGGTATCTAATCC -3' (Illumina, 2013). The $25 \mu \mathrm{L}$ reaction mixture contained $2.5 \mu \mathrm{L}$ sample DNA, $12.5 \mu \mathrm{L}$ Taq Polymerase $(0.5 \mathrm{U}), 5 \mu \mathrm{L}$ forward primer $(1 \mu \mathrm{M})$ and $5 \mu \mathrm{L}$ reverse primer $(1 \mu \mathrm{M})$. For control sample: DNA was replaced with nuclease free water. Samples were vortexed for $30 \mathrm{~s}$. Samples were then placed in the thermocycler S1000 Thermal Cycler (Bio-Rad, Hercules, CA, USA) for PCR according to the following conditions: 1 cycle initial denaturation for $3 \mathrm{~min}$ at $95^{\circ} \mathrm{C}, 25$ cycles denaturation for 30 seconds at $95^{\circ} \mathrm{C}$, annealing for 30 seconds at $55{ }^{\circ} \mathrm{C}$, extension for 30 seconds at $72{ }^{\circ} \mathrm{C}$ and final extension for 5 minutes at $72{ }^{\circ} \mathrm{C}$ (Illumina, 2013). The PCR product together with $1 \mathrm{~kb}$ DNA ladder molecular marker (GeneRuler DNA Ladders, Thermo Fisher Scientific Inc., MA, USA) were run in electrophoresis using a $1 \%$ agarose gel at $80 \mathrm{~V}$ for 60 minutes (Powerpac Basic Power Supply, Bio-Rad, Hercules, CA, USA). The band size for the 165 rRNA gene, including adapters and index sequences was approximately 500 base pairs. The PCR amplicons were 
sent to National Health Laboratory Service for PCR product purification, quantification and Illumina sequencing.

\subsection{Informatic and Statistical Analysis}

The bioinformatic analysis was conducted in Quantitative Insights into Microbial Ecology 2 (QIIME $2^{\mathrm{TM}}$ ) [36]. Forward and reverse raw fastq sequence reads were first merged into individual contigs. The paired reads were subjected to a series of quality control steps where low-quality reads, as well as reads that did not meet the minimum length criterion of 440 base-pairs were filtered out and singletons were removed. Operational taxonomic units (OTUs) were clustered using QIIME 2. The OTUs were assigned using closed reference picking and taxa was assigned using the Silva reference database [37] (Quast et al., 2012). The program USEARCH v.11 [38] was used to remove chimeras and cluster sequences that showed $99 \%$ similarity into the same OTU.

Statistical analysis was conducted on software R v.4.0.2 [39]. Alpha and beta diversity measures, analysing variation in bacterial diversity (Shannon index) and richness were carried out using the Wilcoxon test for pairwise comparisons. Statistical significance was determined by comparison between negative nymphs and adults, as well as positive nymphs and adults under the null hypothesis of no significant difference between groups. The vegan package v.4.5.6 [40] was used to analyse diversity of bacterial communities by performing permutational multivariate analysis of variance (PerMANOVA, adonis function, permutations $=999$, set seed $=1$ ). Weighted unifraction plots were produced by comparing microbial composition in A. hebraeum nymphs and adults that tested positive for Rickettsia, nymphs and adults that tested negative for Rickettsia and a plot with combined (positive and negative) nymphs and adults. An anosim test was performed to test for dissimilarity of microbial communities between and within groups. A Non-metric Multi-dimensional Scaling (NMDS) plot was generated using the vegan package v.4.5.6 [40] to visually support PerMANOVA and anosim outputs. Variable sequencing depth was accounted for by the rarefying raw OTU counts for nymphs and adults negative for Rickettsia and nymphs and adults positive for Rickettsia. All sequences were classified from phylum to genus level using R phyloseq package [41]. The relative abundance bar plots representing phyla from negative and positive nymphs and adults were generated using the Phyloseq R package. Individual relative abundance phyla boxplots were generated using the phyloseq psmelt function. Core microbiota was evaluated at $50 \%$ presence of taxa in the negative and positive groups at $1 \%$ minimum relative abundance, this was accomplished using the $R$ microbiome package v1.10 [42].

\subsection{Ethical Statement}

The study was approved by the University of KwaZulu-Natal Animal Research Ethics Committee, as well as the Department of Agriculture, Land Reform and Rural Development (DALRRD); previously Department of Agriculture, Forestry and Fisheries (DAFF) under Section 20 of the Animal Diseases Act of 1984 (Act No 35 of 1984).

\section{Conclusions}

The evidence presented in this study suggested that A. hebraeum nymphs sampled from Caquba in the Eastern Cape province of South Africa sustained a multifaceted microbiome, which was mainly composed of non-pathogenic microorganisms, and some which can cause tick-borne diseases. The study indicates that $A$. hebraeum is a definitive reservoir and vector for Rickettsia spp. in the Eastern Cape province of South Africa and should therefore be regarded as of zoonotic importance. It is evident that A. hebraeum harboured a Coxiellalike endosymbiont which should be researched further as Coxiella may affect the viability and transmission of other organisms. Multiple infections with these pathogens may result in increased bacterial burden, as well as more severe and diverse clinical manifestation of disease in livestock. A difficulty arises in the analysis and identification of microbial constituents in A. hebraeum due to the excessive abundance of Rickettsia and Coxiella spp. but this can be improved with an increase in sampling effort and thereby sequencing depth. 
Evidence regarding bacteria which may inhibit or promote the transmission of Rickettsia remains inconclusive. However, vector control strategies should be considered. The presence of R. aeschlimannii is the first ever to be recorded in A. hebraeum and further studies should be based on a comparison between the microbiome variation in Rhipicephalus spp. and A. hebraeum.

Author Contributions: Conceptualization of idea, S.M., S.I.T. and J.B.; sample collection D.K. and S.M.; DNA extraction and PCR, D.K.; analysis of data, D.K. and J.B.; manuscript was drafted by D.K. with contribution from all authors. All authors have read and agreed to the published version of the manuscript.

Funding: This research was funded by NIH grant 1R01AI136035 as part of the joint NIH-NSF-USDA Ecology and Evolution of Infectious Diseases program. The funding body had no role in the design of the study and collection, analysis, and interpretation of data and in writing the manuscript.

Institutional Review Board Statement: Ethical considerations were fulfilled by obtaining approval of the study from the Animal Research Ethics Committee, University of KwaZulu Natal (Ref: AREC/056/017).

Data Availability Statement: The data presented in this study are contained within the article.

Acknowledgments: We acknowledge and thank the farmers from Caquba who allowed us to collect tick samples from their cattle.

Conflicts of Interest: The authors declare no conflict of interest.

\section{Appendix A}

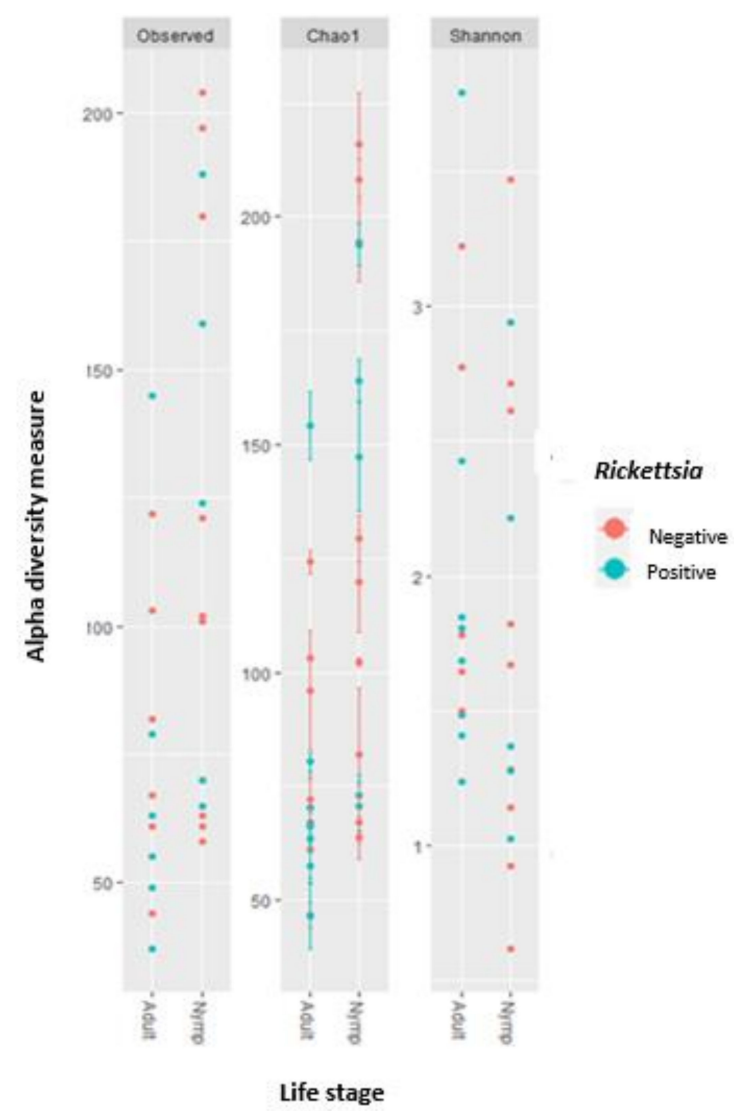

Figure A1. Bacterial alpha diversity measures of Amblyomma hebraeum nymphs and adults negative and positive for Rickettsia africae by means of OTUs. Negative nymphs and adults (pink dots), positive nymphs and adults (blue dots). Solid lines indicate standard error. 


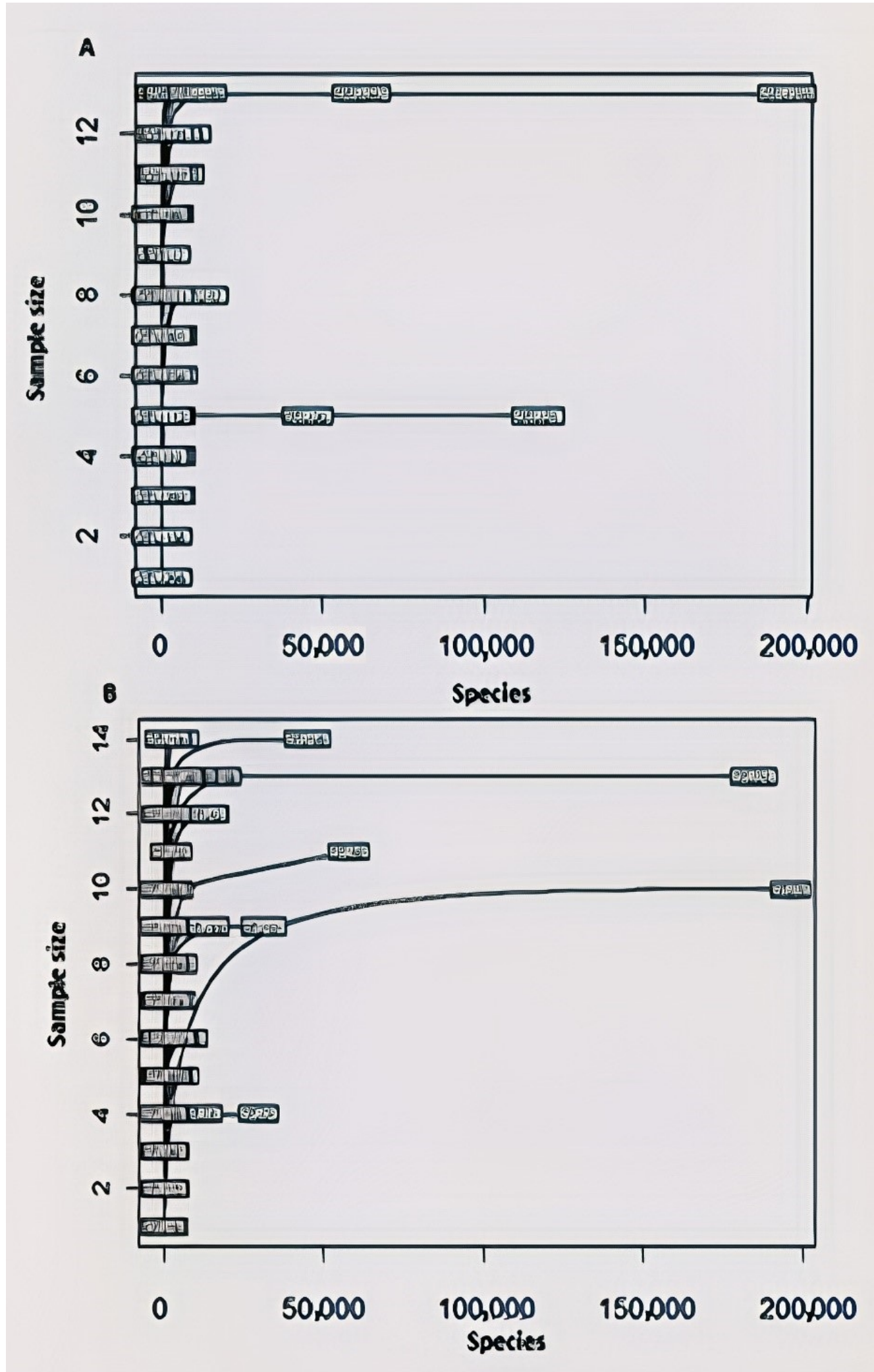

Figure A2. Rarefaction curves indicating sequencing depth of OTUs for Amblyomma hebraeum nymphs and adults negative and positive for Rickettsia africae. (A) Nymphs and adults positive for Rickettsia, (B) Nymphs and adults negative for Rickettsia. The read depth was plotted against mean species diversity of bacterial populations in A. hebraeum nymphs and adults. 
A
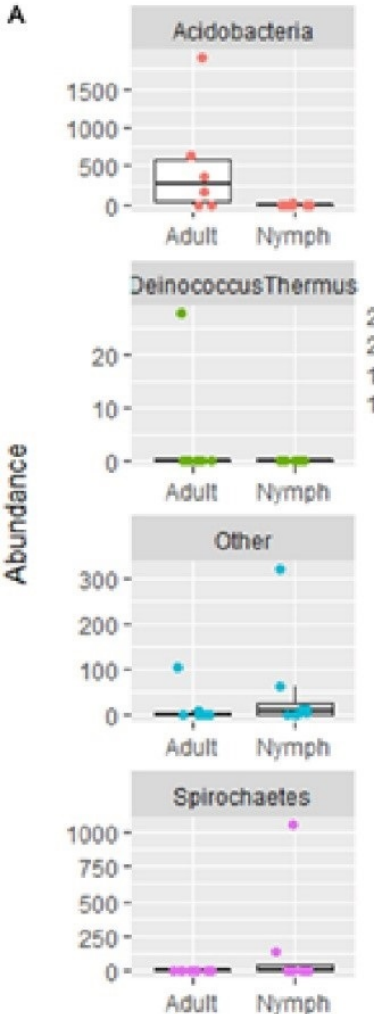

$$
\text { B }
$$
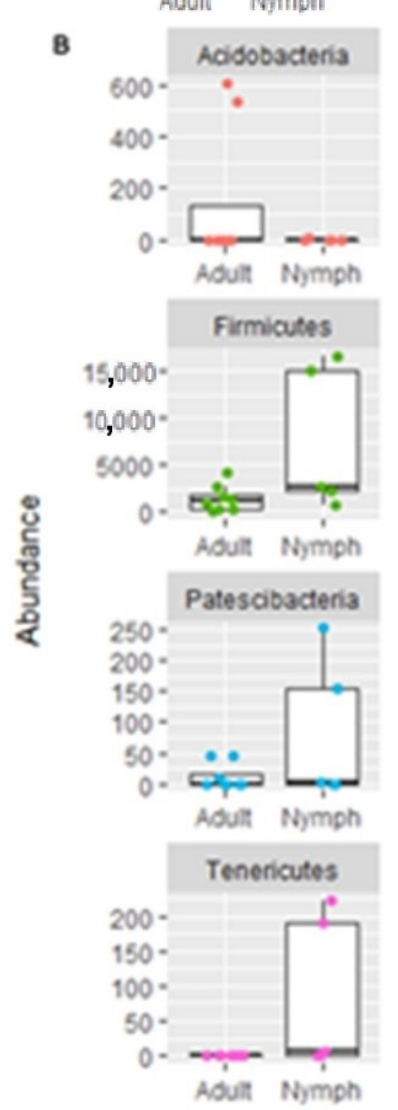
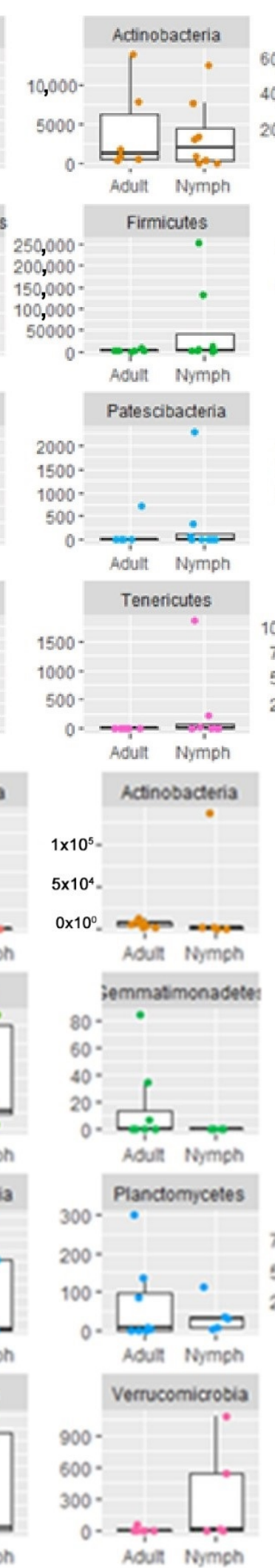
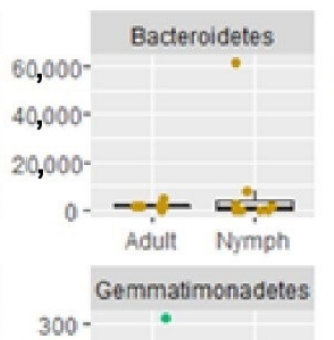

200 -

$100-$
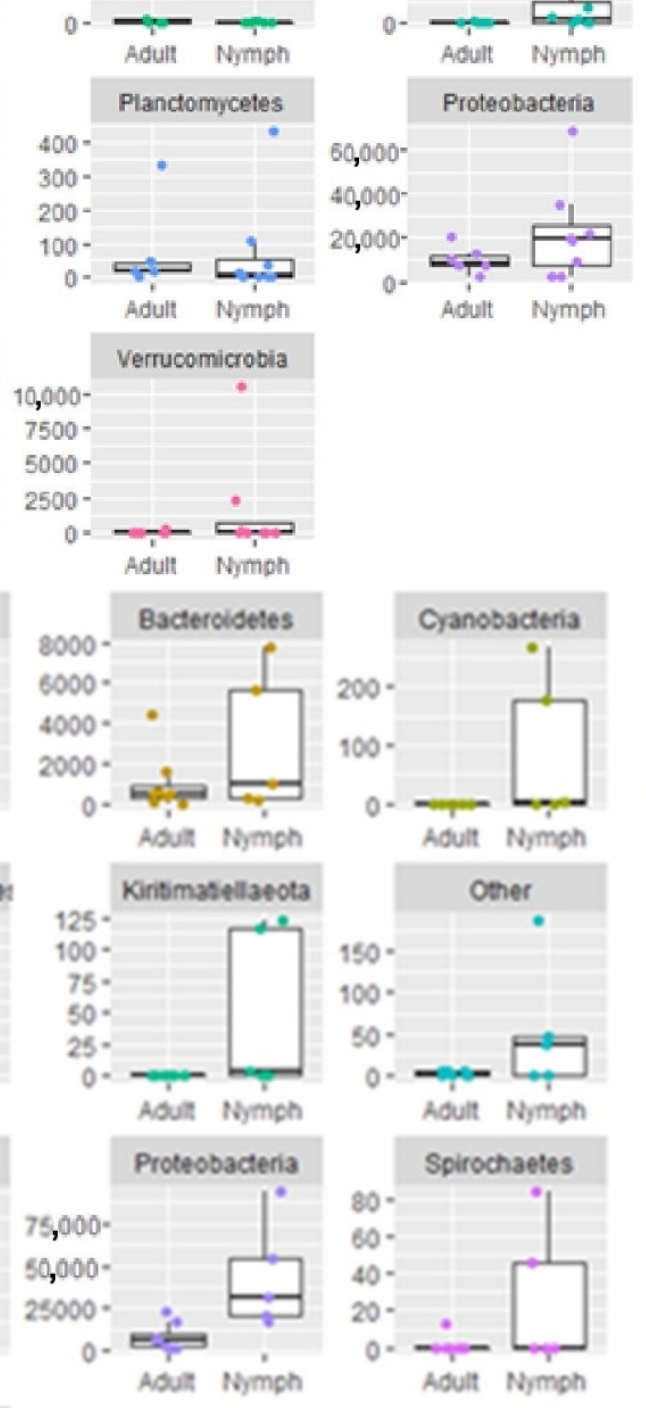

OTU

- Adidobacteria

- Actinobacteria

- Bacteroigetes

- Cyanobacteria

- Firmicules

- Gemmatimonadetes

- Kiramasellaecta

- Other

- Patescibacteria

- Pianctomycetes

- Proteobacteria

- Spirochaetes

- Tenericutes

- Verrucomicrobia

Figure A3. Relative abundance boxplots of bacterial communities according to Phylum classification for Amblyomma hebraeum nymphs and adults negative and positive for Rickettsia africae. (A) Nymphs and adults negative for Rickettsia, (B) Nymphs and adults positive for Rickettsia. Each dot represents a bacterial community. Each colour represents a phylum. Sequences that were not classified into a known phylum were classified as 'Other'. 


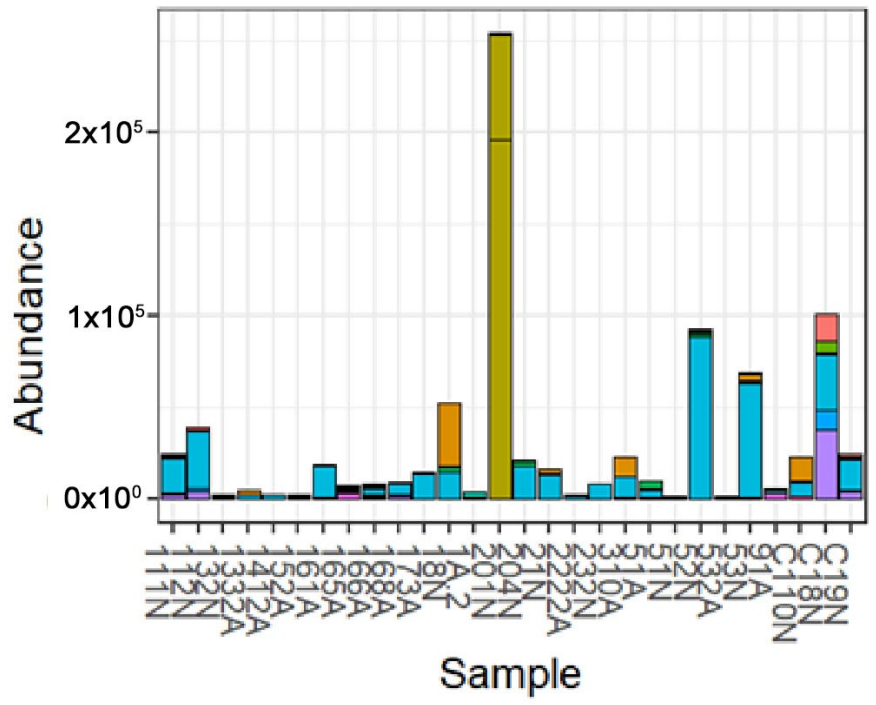

\section{Genus}

[Eubacterium] coprostanoligenes group Arsenophonus

Bacillus

Bacteroides

Coxiella

Pseudomonas

Rickettsia

Rikenellaceae RC9 gut group

Ruminococcaceae UCG-005

Sediminibacterium

Staphylococcus

Figure A4. Relative abundance bar plot representing bacterial communities at genus classification for Amblyomma hebraeum nymphs and adults negative and positive for Rickettsia africae.

Table A1. Metadata information for all ticks used in this study which including species, sample ID, year of collection, sampling site, sample source (environment or cattle), life stage, nutritional status (Engorged Y-Yes; N-No), sex of tick (M-Male; F-Female) and Rickettsia africae status (positive or negative).

\begin{tabular}{|c|c|c|c|c|c|c|c|c|}
\hline Species & Sample ID & Year & Site & Sample Area & Life Stage & $\begin{array}{c}\text { Sex } \\
(M / F)\end{array}$ & $\begin{array}{l}\text { Engorged } \\
(\mathrm{Y} / \mathrm{N})\end{array}$ & $\begin{array}{c}\text { Rickettsia } \\
\text { Status }\end{array}$ \\
\hline Amblyomma hebraeum & $18 \mathrm{~N}$ & 2018 & Caquba & Environment & Nymph & M & $\mathrm{N}$ & Negative \\
\hline Amblyomma hebraeum & $110 \mathrm{~N}$ & 2018 & Caquba & Environment & Nymph & $\mathrm{F}$ & $\mathrm{N}$ & Positive \\
\hline Amblyomma hebraeum & $19 \mathrm{~N}$ & 2018 & Caquba & Environment & Nymph & $\mathrm{F}$ & $\mathrm{N}$ & Positive \\
\hline Amblyomma hebraeum & $112 \mathrm{~N}$ & 2019 & Caquba & Environment & Nymph & M & $\mathrm{N}$ & Positive \\
\hline Amblyomma hebraeum & $111 N$ & 2019 & Caquba & Environment & Nymph & $\mathrm{F}$ & $\mathrm{N}$ & Negative \\
\hline Amblyomma hebraeum & $201 N$ & 2018 & Caquba & Environment & Nymph & M & $\mathrm{N}$ & Negative \\
\hline Amblyomma hebraeum & $21 \mathrm{~N}$ & 2018 & Caquba & Environment & Nymph & M & $\mathrm{N}$ & Negative \\
\hline Amblyomma hebraeum & $53 \mathrm{~N}$ & 2018 & Caquba & Environment & Nymph & M & $\mathrm{N}$ & Negative \\
\hline Amblyomma hebraeum & $204 N$ & 2018 & Caquba & Environment & Nymph & M & $\mathrm{N}$ & Negative \\
\hline Amblyomma hebraeum & $18 \mathrm{~N}$ & 2019 & Caquba & Environment & Nymph & $\mathrm{F}$ & $\mathrm{N}$ & Positive \\
\hline Amblyomma hebraeum & $168 \mathrm{~A}$ & 2019 & Caquba & Cattle & Adult & $\mathrm{F}$ & $\mathrm{N}$ & Negative \\
\hline Amblyomma hebraeum & $165 \mathrm{~A}$ & 2019 & Caquba & Cattle & Adult & M & $\mathrm{N}$ & Positive \\
\hline Amblyomma hebraeum & $91 \mathrm{~A}$ & 2019 & Caquba & Cattle & Adult & $\mathrm{F}$ & $\mathrm{Y}$ & Negative \\
\hline Amblyomma hebraeum & $51 \mathrm{~A}$ & 2019 & Caquba & Cattle & Adult & $\mathrm{F}$ & $\mathrm{N}$ & Negative \\
\hline Amblyomma hebraeum & $161 \mathrm{~A}$ & 2019 & Caquba & Cattle & Adult & $\mathrm{F}$ & $\mathrm{N}$ & Negative \\
\hline Amblyomma hebraeum & $1 \mathrm{~A}$ & 2019 & Caquba & Cattle & Adult & M & $\mathrm{N}$ & Positive \\
\hline Amblyomma hebraeum & $166 \mathrm{~A}$ & 2019 & Caquba & Cattle & Adult & $\mathrm{F}$ & $\mathrm{N}$ & Positive \\
\hline Amblyomma hebraeum & $310 \mathrm{~A}$ & 2019 & Caquba & Cattle & Adult & M & $\mathrm{N}$ & Positive \\
\hline Amblyomma hebraeum & $173 \mathrm{~A}$ & 2019 & Caquba & Cattle & Adult & $\mathrm{F}$ & $\mathrm{Y}$ & Positive \\
\hline Amblyomma hebraeum & $\mathrm{C} 51 \mathrm{~N}$ & 2018 & Caquba & Environment & Nymph & $\mathrm{M}$ & $\mathrm{N}$ & Negative \\
\hline Amblyomma hebraeum & $\mathrm{C} 52 \mathrm{~N}$ & 2018 & Caquba & Environment & Nymph & $\mathrm{M}$ & $\mathrm{N}$ & Positive \\
\hline Amblyomma hebraeum & C532A & 2018 & Caquba & Cattle & Adult & $\mathrm{F}$ & $\mathrm{N}$ & Positive \\
\hline
\end{tabular}


Table A1. Cont.

\begin{tabular}{ccccccccc}
\hline Species & Sample ID & Year & Site & Sample Area & Life Stage & $\begin{array}{c}\text { Sex } \\
\text { (M/F) }\end{array}$ & $\begin{array}{c}\text { Engorged } \\
\text { (Y/N) }\end{array}$ & $\begin{array}{c}\text { Rickettsia } \\
\text { Status }\end{array}$ \\
\hline Amblyomma hebraeum & C132N & 2018 & Caquba & Environment & Nymph & M & N & Negative \\
\hline Amblyomma hebraeum & C133A & 2018 & Caquba & Cattle & Adult & F & N & Negative \\
\hline Amblyomma hebraeum & C141A & 2018 & Caquba & Cattle & Adult & M & N & Positive \\
\hline Amblyomma hebraeum & C152A & 2018 & Caquba & Cattle & Adult & M & N & Negative \\
\hline Amblyomma hebraeum & C222A & 2018 & Caquba & Cattle & Adult & F & N & Positive \\
\hline Amblyomma hebraeum & C232N & 2018 & Caquba & Environment & Nymph & M & N & Negative \\
\hline
\end{tabular}

\section{References}

1. Toledo, Á.; Olmeda, A.; Jado, I.; Gil, H.; Valcárcel, F.; Anda, P.; Escudero, R.; Casado-Nistal, M.; Rodríguez-Vargas, M. Tick-borne zoonotic bacteria in ticks collected from central Spain. Am. J. Trop. Med. Hyg. 2009, 81, 67-74. [CrossRef]

2. Greay, T.; Gofton, A.; Paparini, A.; Ryan, U.; Oskam, C.; Irwin, P. Recent insights into the tick microbiome gained through next-generation sequencing. Parasit. Vectors 2018, 11, 12. [CrossRef]

3. Bonnet, S.; Binetruy, F.; Hernández-Jarguín, A.; Duron, O. The tick microbiome: Why non-pathogenic microorganisms matter in tick biology and pathogen transmission. Front Cell. Infect. Microbiol. 2017, 7, 1-14. [CrossRef] [PubMed]

4. Horak, I.G.; Fourie, L.; Heyne, H.; Walker, J.; Needham, G. Ixodid ticks feeding on humans in South Africa: With notes on preferred hosts, geographic distribution, seasonal occurrence, and transmission of pathogens. Exp. Appl. Acarol. 2002, 27, 113-136. [CrossRef]

5. Walker, A.R.; Bouattour, A.; Camicas, J.; Estrada-Peña, A.; Horak, I.G.; Latif, A.; Pegram, R.; Preston, P. Ticks of Domestic Animals in Africa; Bioscience Reports: Edinburgh, UK, 2003; pp. 2-221.

6. Cazorla, C.; Socolovschi, C.; Jensenius, M.; Parola, P. Tick-borne diseases: Tick-borne spotted fever rickettsioses in Africa. Infect. Dis. Clin. N. Am. 2008, 22, 531-544. [CrossRef] [PubMed]

7. Gubler, D. Vector-borne diseases. Rev. Sci. Tech. Off. Int. Épizoot. 2009, 28, 583-588. [CrossRef]

8. Chitanga, S.; Gaff, H.; Mukaratirwa, S. Tick-borne pathogens of potential zoonotic importance in the southern African Region. J. S. Afr. Vet. Assoc. 2014, 85, 1-3. [CrossRef]

9. Biggs, H.M.; Behravesh, C.B.; Bradley, K.K.; Dahlgren, F.S.; Drexler, N.A.; Dumler, J.S.; Folk, S.M.; Kato, C.Y.; Lash, R.R.; Levin, M.L.; et al. Diagnosis and management of tick-borne rickettsial diseases: Rocky Mountain Spotted Fever and other spotted fever group rickettsioses, ehrlichioses, and anaplasmosis-United States: A practical guide for health care and public health professionals. Morb. Mortal. Wkly. Rep. 2016, 65, 1-44.

10. Tomassone, L.; Portillo, A.; Nováková, M.; De Sousa, R.; Oteo, J.A. Neglected aspects of tick-borne rickettsioses. Parasit. Vectors 2018, 11, 263. [CrossRef]

11. Narasimhan, S.; Fikrig, E. Tick microbiome: The force within. Trends Parasitol. 2015, 31, 315-323. [CrossRef]

12. Hawlena, H.; Rynkiewicz, E.; Toh, E.; Alfred, A.; Durden, L.A.; Hastriter, M.W.; Nelson, D.E.; Rong, R.; Munro, D.; Dong, Q.; et al. The arthropod, but not the vertebrate host or its environment, dictates bacterial community composition of fleas and ticks. ISME J. 2013, 7, 221-223. [CrossRef] [PubMed]

13. Van Treuren, W.; Ponnusamy, L.; Brinkerhoff, R.J.; Gonzalez, A.; Parobek, C.M.; Juliano, J.J.; Andreadis, T.G.; Falco, R.C.; Ziegler, L.B.; Hathaway, N.; et al. Variation in the microbiota of Ixodes ticks with regard to geography, species and sex. Appl. Environ. Microbiol. 2015, 81, 6200-6209. [CrossRef] [PubMed]

14. Estrada-Peña, A.; Gray, J.; Kahl, O.; Lane, R.; Nijhof, A. Research on the ecology of ticks and tick-borne pathogens-Methodological principles and caveats. Front. Cell Infect. Microbiol. 2013, 3, 29. [CrossRef]

15. Ahantarig, A.; Trinachartvanit, W.; Baimai, V.; Grubhoffer, L. Hard ticks and their bacterial endosymbionts (or would be pathogens). Folia Microbiol. 2013, 58, 419-428. [CrossRef]

16. Murrell, A.; Dobson, S.; Lacey, E.; Barker, S. A survey of bacterial diversity in ticks, lice and fleas from Australia. Parasitol. Res. 2002, 89, 326-334. [CrossRef] [PubMed]

17. Torabpour, S.; Soltani, A.; Sadeghi, S.; Dabaghmanesh, T.; Kalantari, M.; Azizi, K. The first detection of Amblyomma hebraeum (Acarina: Ixodidae) in Iran. Vet. Parasitol. Reg. Stud. 2019, 16, e100276. [CrossRef] [PubMed]

18. Jongejan, F.; Berger, L.; Busser, S.; Deetman, I.; Jochems, M.; Leenders, T.; De Sitter, B.; Van der Steen, F.; Wentzel, J.; Stoltsz, H. Amblyomma hebraeum is the predominant tick species on goats in the Mnisi community area of Mpumalanga province South Africa and is co-infected with Ehrlichia ruminantium and Rickettsia africae. Parasit. Vectors 2020, 13, 1-12. [CrossRef]

19. Brinkerhoff, R.J.; Clark, C.; Ocasio, K.; Gauthier, D.; Hynes, W. Factors affecting the microbiome of Ixodes scapularis and Amblyomma americanum. PLoS ONE 2020, 15, e0232398. [CrossRef]

20. Trout-Fryxell, R.; DeBruyn, J. Correction: The microbiome of Ehrlichia-infected and uninfected Lone star ticks (Amblyomma americanum). PLoS ONE 2016, 11, e0155559. 
21. Weinert, L.; Werren, J.; Aebi, A.; Stone, G.; Jiggins, F. Evolution and diversity of Rickettsia bacteria. BMC Biol. $2009,7,1-15$. [CrossRef]

22. Salter, S.J.; Cox, M.J.; Turek, E.M.; Calus, S.T.; Cookson, W.O.; Moffatt, M.F.; Turner, P.; Parkhill, J.; Loman, N.J.; Walker, A.W. Reagent and laboratory contamination can critically impact sequence-based microbiome analyses. BMC Biol. $2014,12,87$. [CrossRef] [PubMed]

23. Rynkiewicz, E.C.; Hemmerich, C.; Rusch, D.B.; Fuqua, C.; Clay, K. Concordance of bacterial communities of two tick species and blood of their shared rodent host. Mol. Ecol. 2015, 24, 2566-2579. [CrossRef]

24. Mtshali, K.; Khumalo, Z.; Nakao, R.; Grab, D.; Sugimoto, C.; Thekisoe, O. Molecular detection of zoonotic tick-borne pathogens from ticks collected from ruminants in four South African provinces. J. Vet. Med. Sci. 2015, 77, 1573-1579. [CrossRef] [PubMed]

25. Varela-Stokes, A.S.; Park, S.H.; Stokes, J.V.; Gavron, N.A.; Lee, S.I.; Moraru, G.M.; Ricke, S.C. Tick microbial communities within enriched extracts of Amblyomma maculatum. Ticks Tick Borne Dis. 2018, 9, 798-805. [CrossRef]

26. Clow, K.; Weese, J.; Rousseau, J.; Jardine, C. Microbiota of field collected Ixodes scapularis and Dermacentor variabilis from eastern and southern Ontario, Canada. Ticks Tick Borne Dis. 2018, 9, 235-244. [CrossRef] [PubMed]

27. Karim, S.; Budachetri, K.; Mukherjee, N.; Williams, J.; Kausar, A.; Hassan, M.J.; Adamson, S.; Dowd, S.E.; Apanskevich, D.; Arijo, A.; et al. A study of ticks and tick-borne livestock pathogens in Pakistan. PLoS Negl. Trop. Dis. 2017, 11, e0005681. [CrossRef] [PubMed]

28. Magaia, V.; Taviani, E.; Cangi, N.; Neves, L. Molecular detection of Rickettsia africae in Amblyomma ticks collected in cattle from southern and central Mozambique. J. Infect. Dev. Ctries. 2020, 14, 614-622. [CrossRef]

29. Zolnik, C.P.; Prill, R.J.; Falco, R.C.; Daniels, T.J.; Kolokotronis, S.O. Microbiome changes through ontogeny of a tick pathogen vector. Mol. Ecol. 2016, 25, 4963-4977. [CrossRef]

30. Menchaca, A.; Visi, D.; Strey, O.; Teel, P.; Kalinowski, K.; Allen, M.; Williamson, P. Preliminary assessment of microbiome changes following blood-feeding and survivorship in the Amblyomma americanum nymph-to-adult transition using semiconductor sequencing. PLoS ONE 2013, 8, e67129. [CrossRef]

31. Pretorius, A.M.; Birtles, R.J. Rickettsia aeschlimannii: A new pathogenic spotted fever group Rickettsia, South Africa. Emerg. Infect. Dis. 2002, 8, 874. [CrossRef]

32. Subramanian, G.; Sekeyova, Z.; Raoult, D.; Mediannikov, O. Multiple tick-associated bacteria in Ixodes ricinus from Slovakia. Ticks Tick Borne Dis. 2012, 3, 406-410. [CrossRef]

33. Simpson, G.J.; Quan, V.; Frean, J.; Knobel, D.L.; Rossouw, J.; Weyer, J.; Marcotty, T.; Godfroid, J.; Blumberg, L.H. Prevalence of selected zoonotic diseases and risk factors at a human-wildlife-livestock interface in Mpumalanga province, South Africa. Vector Borne Zoonotic Dis. 2018, 18, 303-310. [CrossRef]

34. Pillay, A.D.; Mukaratirwa, S. Genetic diversity of Rickettsia africae isolates from Amblyomma hebraeum and blood from cattle in the Eastern Cape province of South Africa. Exp. Appl. Acarol. 2020, 82, 529-541. [CrossRef] [PubMed]

35. Beard, D.; Stannard, H.J.; Old, J.M. Morphological identifcation of ticks and molecular detection of tick-borne pathogens from bare-nosed wombats (Vombatus ursinus). Parasit. Vectors 2021, 14, 60. [CrossRef] [PubMed]

36. Bolyen, E.; Rideout, J.R.; Dillon, M.R.; Bokulich, N.A.; Abnet, C.C.; Al-Ghalith, G.A.; Alexander, H.; Alm, E.J.; Arumugam, M.; Asnicar, F.; et al. Reproducible, interactive, scalable and extensible microbiome data science using QIIME 2. Nat. Biotechnol. 2019, 37, 852-857. [CrossRef]

37. Quast, C.; Pruesse, E.; Yilmaz, P.; Gerken, J.; Schweer, T.; Yarza, P.; Peplies, J.; Glöckner, F.O. The SILVA ribosomal RNA gene database project: Improved data processing and web-based tools. Nucleic Acids Res. 2012, 41, D590-D596. [CrossRef] [PubMed]

38. Edgar, R.C. Search and clustering orders of magnitude faster than BLAST. Bioinformatics 2010, 26, 2460-2461. [CrossRef] [PubMed]

39. R Core Team. A Language and Environment for Statistical Computing; R Foundation for Statistical Computing: Vienna, Austria, 2016.

40. Oksanen, J.; Kindt, R.; Legendre, P.; O’Hara, B.; Stevens, M.H.H.; Oksanen, M.J.; Suggests, M.A.S.S. The vegan package. Community Ecol. Package 2007, 10, 719.

41. McMurdie, P.J.; Holmes, S. Phyloseq: An R package for reproducible interactive analysis and graphics of microbiome census data. PLoS ONE 2013, 8, e61217. [CrossRef]

42. Lahti, L.; Shetty, S.; Blake, T.; Salojarvi, J. Tools for Microbiome Analysis in R, Version 1.5.28. 2017. Avaliable online: https:/ / microbiome.github.io/tutorials/ (accessed on 4 July 2021). 